\title{
EXPLORING THE DIFFERENCE BETWEEN TURKISH AND BOSNIAN STUDENTS IN TRIANGULAR LOVE SCALE
}

\section{Selvira Drahanović*}

Anela Hasanagić*

\begin{abstract}
Numerous studies show that different cultures experience and express emotions in different ways. Some cultures tend to express emotions without restrictions while some others try to suppress the overt expression of emotions. These differences are particularly more manifest when Eastern and Western cultures are compared. Defining love differs between different cultures what makes it difficult to determine cultural differences in the concept of love. This might serve as a basis of prejudices about some nations in relation to how they perceive love. The main aim of this study is to explore differences between Turkish and Bosnian students on triangular love scale. The term love is operationalized by Sternberg's triangular theory of love scale which includes intimacy, passion and commitment component of love. Using quasi-experimental design we tested gender differences, the length of current relationship and correlation between them on overall scale and individual subscales. The sample consisted of 87 Turkish (22 males and 65 females) and 64 Bosnian students (23 males and 41 females) total 151 students $(\mathrm{N}=151)$. Results of the study show statistically significant differences between Turkish and Bosnian students on two dimensions in Sternberg Triangular Love Scale, Intimacy and Passion. Bosnian students scored higher on these subscales. Study results suggest that there are no statistically significant differences between males and females in any subscale. The length of love relationship is positively correlated with intimacy, which indicates that the length of connections weakly associated with intimacy, and that is not associated with the passion and the decision of commitment, suggesting longer relationship does not mean more romantic relationship, and vice versa.
\end{abstract}

Keywords: Love; Relationship; Theories of Love; Triangular Theory of Love and Culture

\section{Introduction}

While discussing emotions, psychologist often talk about subjective relations toward things, people, events and own behaviors (Rot, 2004). Human beings have some sort of emotions towards almost everything and anything, even a state of not caring for or neutrality reflects an emotion. Thus, there is an emotional relation towards everyone and everything constantly. According to Corsini and Aurebach (1998) "emotions are strong mental states, usually involving excitement or high energy, that give rise to feeling and passion" (p. 260). Emotions can be positive and negative, with different intensity ranging from mild excitement to the eruption of emotion.

All emotions consists of cognitive, physiological and behavior components (Rathus, 2000). Cognitive components means that people perceive some source toward which they develop certain emotion, physiological component is the reaction of body, like 
reaction of sympathetic or parasympathetic, while behavior comes as the reaction, and according to which environment becomes aware of the emotion of human being.

Emotions are many and that is why the number and definitions of emotions differ from theorist to theorist, and varies from time to time. Carlson and Hatfield (1992) state that in Ancient China, there was a belief that there are four basic emotions: happiness, anger, sadness and fear (stated in Rathus, 2000). Watson (1924) initially thought that there are only three basic emotions: fear, rage and love (Rathus, 2000), while Paul Eckman (1992) and Robert Plutchik (1984) maintained that, besides those emotions, there are many more (Rathus, 2000). Those disparities originated a need to define universality in developing emotions.

In 1932, Bridges defined universality in developing of emotions as arousal (which begins to develop at the beginning of children's life), from which other emotions are developed (satisfaction and dissatisfaction firstly, and later on, other emotions like rage, proud, love, fear develop (Rot 2004). Even though there are several classifications of emotions, most of the researchers consent about two basic categories: basic, or primary and complex, or secondary emotions. Primary emotions are emotions which develop early in life, such as: fear, anger, happiness and grief or sorrow. Some researchers add pleasure into this group. Complex emotions developed later in life and, as stated by some, (Plutchik for example) are emotions which develop as a result of combination of some basic/primary emotions. Secondary or complex emotions are the ones which are directed to other people (love, hate, jealousy, envy, compassion), toward own personality (success, pride, shame, guilt) and esthetic emotions (respect, awe, veneration) (Rot, 2004).

Scientists exploring emotions offer a few approaches or theories of emotions. Each theory is a unique approach in explaining development of emotions and emotional differentiation. Hence, in order to operationally define or measure and study emotions, it is important to consider one approach or theoretical perspective. James- Lange, CannonBard and Cognitive and Attribution theories of emotions are the most influential theories of emotions often cited in literature.

a) The James-Lange Theory: according to which, stimuli produces bodily changes that in turn generate emotions. This theory suggests that stimuli are keys to physical reactions as well as for emotions.

b) The Cannon-Bard Theory: according to this theory, when emotion-producing stimulus is received in brain, centers in the thalamus and hypothalamus send out simultaneous signals to both external muscles and internal organs and back to the cortex. The muscles and organs make the physiological reactions casing emotions, while the cortex interprets the signal as emotion. According to Cannon, events that caused emotions give rise to arousal of the sympathetic nervous system, and this arousal regulates and prepares organism to fight or flee reaction.

c) Cognitive and Attribution Theories of Emotion. These theories support interaction between cognitive (intellectual) and physiological (bodily) influences. Every emotion is aroused by acknowledging/knowing something and appraising it.

Epiphany: Journal of Transdisciplinary Studies, Vol. 7. No. 2, (2014) (C) Faculty of Arts and Social Sciences 
Just like in any psychological process, genetic and environmental factors are important factors in emotions as well. On one hand, theories which focus on impact of genetics factors find their evidences in research about neurological basis of emotions, genetics, and universal emotional development of human being. On the other hand, theories that support environmental factors point out to the research findings about impact of learning process in developing emotions, as well as cultural diversity in expressing emotions. In this research, we take the stand and go in line with the second theorists and explore the cultural differences in love among Turkish and Bosnian students.

\section{Cultural Differences in Emotions}

Although emotions are universal phenomena, culture plays important role in expression of emotions. Bridges (1932, as cited in Rot 2004), shows that emotions are developed in the same way in all human beings. Firstly arousal begins which later turns into the feeling of satisfaction or dissatisfaction followed by emergence of basic emotions like fear, happiness, disgust etc. This process is universal. However, with some emotional states, different cultures point to different antecedent situations (the way they are versed in, the reactions they agitate and the way they are perceived by the society, for example).

Different cultures have different ways of expressing their emotions. Cultural difference in displaying emotions comes from differences in emotional display rules which are "specific cultural norms or rules that regulate how, when and where a person expresses emotions and how much emotional expression is appropriate" (Plotnik \& Kouyoumdjian 2011, p. 367). Some cultures tend to express their emotions freely, while others tend to hold their emotions back (Niedenthal, et al. 2006, p. 306). This difference is very prominent when we compare Eastern and Western cultures.

Plotnik \& Kouyoumdjian (2011) cite several researches about cultural differences in emotional expression. For example, Americans generally display rules which encourage free emotional expression. Eastern cultures, on the other hand, like Japanese or Russians, do not show emotions as freely as Westerners. Japanese for example, cover their mouth when laughing, while Russians rarely laugh in public, only in private gatherings. Eastern cultures are usually perceived as more introverted and collectivistic. Therefore they tend to show less emotion in order to keep the well-being of the group intact. Members of Western cultures express their emotions in order to help themselves even if that requires negative emotions towards the others. These significant diverse types of emotional expression based on culture symbolize the opposite in ways of emotional expression which seem to serve and function well in own cultures. Nevertheless, just because Eastern cultures tent to be more collectivistic in nature does not mean they do not express their emotions at all. It is more that expression of emotions in Eastern cultures is less explicit and obvious and restrained to a more personal and private settings.

The importance and impact of romantic/love relationships evidently differs from culture to culture. Each culture manifestly and latently prescribes "expected time for" and "appropriate characteristics" of romantic relationships. The so called free love practiced with precautionary measures in Eastern cultures is often viewed as an inappropriate

Epiphany: Journal of Transdisciplinary Studies, Vol. 7. No. 2, (2014) @ Faculty of Arts and Social Sciences 
behavior by parents and teachers and is subject to parental discipline. Adolescents are habitually faced with significant restrictions and preventive measure from parents and society at large for early dating. Therefore romantic involvement for Eastern adolescents appears discouraged and less prevalent compared to those in Western cultures, especially, in countries where Islamic values dominate. Islam restricts sexual contacts and pleasures to spouses in marriage only and forbids pre-marital relations involving physical contact. However, contrary to the western countries, early marriages are favored and quite common in Eastern cultures. Nonetheless, this practice frequently criticized by Westerners, it has some positive impacts as well (less sexual partners and thus less risks for STDs for example).

\section{Theories of Love}

One of the most important and significant emotions, which also represents one of the basic needs of all humans is love. However, explaining and understanding how and why love happens and occurs, is not easy. Brown (1987) says, emotions as current mental states are "abnormal bodily changes caused by the agent's evaluation or appraisal of some object or situation that the agent believes to be of concern to him or her" (p. 14.). Badhwar (2003) similarly understands love to be a matter of "one's overall emotional orientation towards a person, the complex of perceptions, thoughts, and feelings"; as such, love is a matter of having a certain "character structure" (p. 46). Central to this complex emotional orientation, as Badhwar argues, is what she calls the "look of love": "an ongoing [emotional] affirmation of the loved object as worthy of existence...for her own sake" (p. 44), an affirmation that involves taking pleasure in your beloved's wellbeing, providing to the beloved reliable testimony concerning the quality of the beloved's character and actions (p. 57).

The term ,love, is so frequent and common in use everywhere around us, in movies, soap operas, advertisements and real life situations and personal stories. Love is an emotion of strong affection and personal/intimate attachment. Love is also said to be a virtue representing all human kindness, compassion and affection, or the unselfish loyal and benevolent concern for the good of another (family, friends, and humankind in general (characteristic to human beings). Love may also be described as compassionate and affectionate deeds and care shown towards other humans, one's self or animals.

The term "love" can have a variety of related but distinct meanings within different contexts. Different languages often use multiple terms to express some of the different concepts. Thus, universal conceptualization of love is complicated, what has lead to emergence of numerous theories of love such as: the color wheel, romantic love, compassionate/passionate love, triangular theory of love.

The color wheel model of love, developed by Lee who maintains that love styles are similar to the primary colors red, blue and yellow, whose mix creates the secondary colors like orange, green and purple. Lee (1973) proposed three primary styles of loving, eros, ludos and storge. The eros kind of love, usually portrayed by media in romantic novels and movies, usually is somehow one sided and generally means hopeless romantic

Epiphany: Journal of Transdisciplinary Studies, Vol. 7. No. 2, (2014) @ Faculty of Arts and Social Sciences 
loving the ideal person. One sided love usually leads to disappoints. Ludos type of love refers to the love as a play/game (Casanova for example, whose aim is to have many partners. Lee's last type of love is storge which refers to love build on friendship. This type of love started gradually as friendship which later on turned into intimate relationship. Compared the eros and ludos type of love, storge tends to endure the longest.

Color wheel model of love, as proposed by Lee, occurs by mixing the primary styles. For example, mixing of eros and ludos creates manic or obsessive love, which can be the source of jealousy and possessiveness. On the other hand mixing the ludos and storge type of love brings pragma love. Pragma love is realistic and practical love based on choosing a partner for practical reason, 'good on paper'. Mixing of eros and storge leads to agape type of love which is often experienced as a spiritual, selfless love for the sake of God and not the other person.

Trying to explain the difference between liking and loving, Rubin $(1970,1973)$ proposes romantic love to be composed of attachment, caring and intimacy. Attachment (primal, very strong emotional bond developed early in childhood between a baby and primary care giver transferred into adult relationships) is the need to receive care, approval and physical contact with the other person (desired and beloved). Caring involves esteeming the other persons' needs and happiness as much as your own. Intimacy refers to the sharing of thoughts, desires, and feelings with the other, cherished and beloved person.

Hatfield's (1993) compassionate versus passionate theory of love tries to explain that how people's feelings towards each other are different in allusion to different types of love. Theorists point to the two fundamental types of love, passionate and compassionate. While compassionate love develops from the mutual feelings of respect and understanding between the couple, passionate love refers to the state of intense longing for a union with another, involving subjective feelings, expressions, patterned physiological process, inclined deeds and active behaviors (Hatfield, 1994). This love can be reciprocated (resulting in union with the other) or unrequited (resulting in separation followed by emptiness, anxiety or despair (Hatfield, 1994). Unlike compassionate love, the passionate love does not last for long. Factors like similarity, readiness, deep and secure attachment are important in development of these two types of love.

The Reiss's (1960) Wheel Theory is a sociological theory of love proposing that love develops in stages: rapport, self evaluation, mutual dependency and personality need fulfillment. Rapport emerges when people develop rapport with each other based upon their cultural backgrounds of similar upbringing, social class, religion and education. Rapport is fundamental because without it, as love theory thinkers believe, would-be lovers do not have enough in common to establish even the first spark of an interest in each other. The second, self-revelation stage helps a couple grow closer together. Love is possible because while growing closer each person feels more at ease he or she is more likely to discuss hopes, desires, fears, ambitions and even might engage in sexual activities during this stage. Becoming closer leads to more intimate what may develop into a mutual dependency upon each other leading to exchange of ideas, jokes, and sexual desires. Stage they the couple begins to experience personality need fulfillment, when

Epiphany: Journal of Transdisciplinary Studies, Vol. 7. No. 2, (2014) (C Faculty of Arts and Social Sciences 
partners confide in one another, make mutual decisions, support each other's ambitions and boost each other's self-confidence is Reiss's last stage of love.

Borland (1975) modified Reiss's theory suggesting love to be viewed as clock springs, suggesting the stages can be repeated throughout the relationship. This means the stages can be repeated more times, mistakes can be reduced and the relationship can be improved. Hence, as Borland (1975) states, relationships can wind up and unwind several times as love grows and progresses or declines and deteriorates.

Sternberg (1986) in a form of a triangle, pictures three important components in love, intimacy, passion and commitment. The intimacy encompasses feelings of attachment, closeness, connectedness and bonding in intimate relationship. Passion on the other hand generally includes motivation and consists of the drives connected to sexual attraction and limerence. The component in Sternberg's triangular theory of love is commitment. At short term level, commitment encompasses the decision to remain with a person and the shared achievements and plans made at the long term level.

The elements of intimacy and commitment are usually seen as a stable in a relationship which passion is the quite different and it is not stable as the intimacy and commitment. Intimacy and passionate occur in a relationship when people show patience with each which serves as foundation for long term relationship. On the other hand, lone passion creates infatuation, what puts a relationship at risk. In terms of passion in triangular theory of love, it is important to point out that even though people commit to their feelings at the beginning of their relationship, having passion for each other only does not mean the relationship will survive and succeed.

Nevertheless it is important to note that people differ in experiencing and perceiving these three components. A person can be aware of a passion towards somebody but the intimacy and commitment might be lacking because they require time and other variables. These components are often combined and result in different types of love. Different combination of intimacy, passion and commitment may lead to following types of love: liking, infatuation, empty love, romantic love, companionate love, fatuous love and consummate love and non-love.

As Sternberg says, liking characterizes true friendships, in which a person feels a bonding, warmth, and closeness with another person without intense passion or long-term commitment. Infatuated love refers to feelings or the "love at first sight." This type of love requires no intimacy and the commitment therefore it may suddenly disappear. Strong love might sometimes, deteriorate into an empty love in which commitment remains, but the intimacy and passion have died. This is particularly common in cultures which practice arranged marriages where relationships often begin as empty love. When couples are involved romantically and bonded emotionally and physically through passionate arousal, then we speak about romantic love. Companionate love, on the other hand, is often found in marriages in which the passion faded but a deep affection and commitment still remain. Companionate love is characteristic to a relationship build with someone you share your life with, but sexual or physical desire towards the person are absent. This type

Epiphany: Journal of Transdisciplinary Studies, Vol. 7. No. 2, (2014) (C Faculty of Arts and Social Sciences 
of love is stronger than friendship because of the extra element of commitment. The love ideally shared between family members is a form of companionate love, as is the love between deep friends or those who spend a lot of time together in any asexual but friendly relationship. Fatuous love can be exemplified by a whirlwind courtship and marriage in which a commitment is motivated largely by passion, without the stabilizing influence of intimacy. Aside from these types of love there is also consummate love. Representing the ideal relationship many people strive for but only a few achieve, consummate love is the complete form of love. However, as Sternberg cautions, maintaining consummate love may be even harder than achieving it. He accentuates the importance of converting the components of love into action, because "without expression even the greatest of loves can die" (1988, p. 341). Also, consummate love may not be permanent because if passion dies over time, this love may change into companionate love. Finally, when there is no intimacy, passion, or decision/commitment, then we speak about no love (feelings about a stranger on the bus sitting or standing next to us).

The triangular theory of love helps to explain and understand how interpersonal relationships develop. It is important to mention that relationships based on multiple components of love are more likely to survive compared to those based on a single element.

\section{Research Goals and Hypothesis}

Goals:

1. To investigate the differences between Turkish and Bosnian students on Triangular scale of Love

2. To explore the gender differences in Triangular Scale of Love.

3. To explore correlation between the length of relationship and three dimension of love according to Triangular Theory of love

Hypothesis:

1. There are no statistically significant differences between Turkish and Bosnian students in three aspects of Triangular Theory of Love.

2. There are no statistically significant differences between males and females in results on Triangular Scale of Love.

3. There is no statistically significant correlation between length of relationship and three aspects of Triangular Theory of Love.

\section{Methodology}

Participants

For the purpose of this research, we have used students from International University of Sarajevo (IUS) and University in Zenica. All participants were informed about the purpose of the research. Participation was voluntary, students were asked to volunteer to fill the questionnaires distributed to them, ensuring the privacy of their data and using results for research purpose only. Using convenient sampling method, some students participated in the study at University premises, after classes, in canteen, at cafe, some in boys and girls dormitories, and some took the questionnaire home. In the end, as pointed in table below we had 151 participants in total. 
Table 1. The table about the number of participants according to the two independent variables

\begin{tabular}{|l|l|l|l|l|}
\hline \multicolumn{2}{|c|}{} & \multicolumn{2}{|l|}{ gender } & \\
\cline { 3 - 4 } \multicolumn{2}{|c|}{} & male & female & Total \\
\hline nationality & Turkish & 22 & 65 & 87 \\
& Bosnian & 23 & 41 & 64 \\
\hline Total & 45 & 106 & $\mathbf{1 5 1}$ \\
\hline
\end{tabular}

\section{Instruments used}

a) Socio-demographic questionnaire - which gives main information about gender, nationality, religiosity, number of romantic relationships, the length of romantic relationships

b) Triangular Love Scale (TTLS) (Sternberg, 1988). TTLS is a 45 -items scale measuring the three components of love, intimacy, passion and commitment. Each component is measured by a 15 item subscale. Each scale is rated on 9-point Likert scales ( $1=$ "not at all," $5=$ "moderately," and $9=$ "extremely"). TTLS is reported with high internal consistency, alpha coefficients for three subscales are above 0.90 (Tzeng, 1993.).

\section{Procedure}

Well trained students did field research. Participants were asked to be honest and volunteer to fill the questionnaire. Research took place at university premises, participants were given the questionnaire to take home or to dormitory, fill and return to researcher. The same procedure was used for Turkish and Bosnian students.

\section{Results and Discussion}

1. Cultural and gender differences in three aspects of Triangular Scale of Love

For testing the first two hypotheses, we used multivariate ANOVA with fixed factors Nationality and Gender, and dependent variables: Intimacy, Passion and Commitment. Results are presented in table below.

\begin{tabular}{|c|c|c|c|c|c|}
\hline & nationality & $\mathrm{N}$ & Mean & Std. Deviation & $\begin{array}{|ll|}\text { Std. } & \text { Error } \\
\text { Mean }\end{array}$ \\
\hline \multirow[t]{2}{*}{ intimacy } & Turkish & 87 & 7,0755 & 1,37665 & \begin{tabular}{|l|l|}
, 14759 \\
\end{tabular} \\
\hline & Bosnian & 64 & 7,6083 & 1,29601 &, 16200 \\
\hline \multirow[t]{2}{*}{ passion } & Turkish & 87 & 6,0032 & 1,79287 & ,19222 \\
\hline & Bosnian & 64 & 6,9566 & 1,57167 & , 19646 \\
\hline \multirow[t]{2}{*}{ commitment } & Turkish & 87 & 7,8210 & 8,43975 & ,90484 \\
\hline & Bosnian & 64 & 7,8002 & 1,55950 & ,19494 \\
\hline
\end{tabular}


Table 3. Group Statistics for Gender

\begin{tabular}{|ll|r|r|r|l|}
\hline & gender & $\mathrm{N}$ & Mean & Std. Deviation & $\begin{array}{c}\text { Std. Error } \\
\text { Mean }\end{array}$ \\
\hline intimacy & male & 45 & 7,1808 & 1,43753 &, 21429 \\
& female & 105 & 7,3801 & 1,31180 &, 12802 \\
\hline passion & male & 45 & 6,0918 & 1,82978 &, 27277 \\
& female & 105 & 6,5585 & 1,72247 &, 16810 \\
\hline commitment & male & 45 & 7,1982 & 1,84960 &, 27572 \\
& female & 105 & 8,0970 & 7,65716 &, 74726 \\
\hline
\end{tabular}

Table 4. Tests of Between-Subjects Effects

\begin{tabular}{|c|c|c|c|c|c|c|}
\hline Source & Dependent Variable & $\begin{array}{|lr|}\text { Type } & \text { III } \\
\text { Sum } & \text { of } \\
\text { Squares } & \\
\end{array}$ & $\mathrm{df}$ & Mean Square & $\mathrm{F}$ & Sig. \\
\hline \multirow{3}{*}{$\begin{array}{l}\text { Corrected } \\
\text { Model }\end{array}$} & intimacy & $15,370^{\mathrm{a}}$ & 3 & 5,123 & 2,925 &, 036 \\
\hline & passion & $50,373^{b}$ & 3 & 16,791 & 5,945 &, 001 \\
\hline & commitment & $45,407^{\mathrm{c}}$ & 3 & 15,136 &, 355 &, 786 \\
\hline \multirow[t]{3}{*}{ Intercept } & intimacy & 6628,681 & 1 & 6628,681 & $3,784 \mathrm{E} 3$ &, 000 \\
\hline & passion & 5016,425 & 1 & 5016,425 & $1,776 \mathrm{E} 3$ &, 000 \\
\hline & commitment & 7181,166 & 1 & 7181,166 & 168,336 &, 000 \\
\hline \multirow[t]{3}{*}{ nationality } & intimacy & 9,853 & 1 & 9,853 & 5,624 &, 019 \\
\hline & passion & 43,036 & 1 & 43,036 & 15,237 &, 000 \\
\hline & commitment & 5,340 & 1 & 5,340 &, 125 &, 724 \\
\hline \multirow[t]{3}{*}{ gender } & intimacy & 2,547 & 1 & 2,547 & 1,454 &, 230 \\
\hline & passion & 10,580 & 1 & 10,580 & 3,746 &, 055 \\
\hline & commitment & 23,267 & 1 & 23,267 &, 545 &, 461 \\
\hline \multirow{3}{*}{$\begin{array}{l}\text { nationality } \\
* \text { gender }\end{array}$} & intimacy &, 542 & 1 &, 542 &, 309 &, 579 \\
\hline & passion & 3,324 & 1 & 3,324 & 1,177 &, 280 \\
\hline & commitment & 19,460 & 1 & 19,460 &, 456 &, 500 \\
\hline \multirow[t]{3}{*}{ Error } & intimacy & 255,770 & 146 & 1,752 & & \\
\hline & passion & 412,364 & 146 & 2,824 & & \\
\hline & commitment & 6228,307 & 146 & & & \\
\hline \multirow[t]{3}{*}{ Total } & intimacy & 8309,127 & 150 & & & \\
\hline & passion & 6642,245 & 150 & & & \\
\hline & commitment & 15463,943 & 150 & & & \\
\hline \multirow{3}{*}{$\begin{array}{l}\text { Corrected } \\
\text { Total }\end{array}$} & Intimacy & 271,140 & 149 & & & \\
\hline & passion & 462,737 & 149 & & & \\
\hline & commitment & 6273,715 & 149 & & & \\
\hline
\end{tabular}

\footnotetext{
a. R Squared = ,057 (Adjusted R Squared = ,037)

b. R Squared =,109 (Adjusted R Squared = ,091)

c. $\mathrm{R}$ Squared $=, 007$ (Adjusted $\mathrm{R}$ Squared = $-, 013)$
}

Epiphany: Journal of Transdisciplinary Studies, Vol. 7. No. 2, (2014) (C Faculty of Arts and Social Sciences 
These hypotheses were also tested using simple ANOVA, and results are the same. Results show there is statistically significant difference on Intimacy and Passion subscales of love between Turkish and Bosnian students. Bosnian students have higher results in subscales of Intimacy and Passion. There is no statistically significant difference in subscale of Commitment.

This means that Bosnian students evaluate their relationships like more intimate and passionate than Turkish students. This is probably due to the impact of western culture in Bosnian society. Bosnia and Herzegovina is in between, the East and West and is influenced by both (where the West influence is more manifest in terms of clothing, fashion, music, but also identification systems. In Bosnia and Herzegovina people strive more towards Western vales than to Eastern. Therefore, Bosnian culture can be observed as more Western.

Also, it is important to mention that Bosnian participants are students of Islamic Pedagogical Faculty (where most girls practice Islamic clothing-wear hijab), just like participants from IUS (of Turkish origin), so both groups share religious beliefs and attitudes toward religion obligations.

Western cultures are more open towards love and intimate/romantic relationship apparently and their practices are observed differently than in Eastern cultures (especially Middle East cultures which is more Islamic). In Islam it is forbidden to have intimate relationship before marriage and outside the wedlock. Since most of our participants are not married, this had impact on results and on participant's perception of love in general. Having romantic relationship in Islam allowed as far as it does not involve physical contact of any kind. Islam strictly forbids physical involvement with the opposite sex before the marriage and outside the wedlock. Even though Bosnian students are Muslims, and studying at Islamic Pedagogical Faculty, it seems that living in Bosnia (being a part of Europe and European culture) "melted" their perception of what their religion forbids and they do not observe these rules in the same way the Turks do. It seems that Turkish students adhere to religious rules more, are more traditional hence their relationships are less intimate and passionate than Bosnian students' relationships.

Bosnian culture seems to be more influenced by Western culture. Unlike some Muslim societies (whose cultures seem more strict in following religious rules, i.e., in terms of dress code, Islamic clothing or clear and strict rules on man-women relationships), Western culture is more liberal. Western culture is more lenient accepting and even encouraging romantic/intimate and passionate relationship. However, we did not investigate whether Bosnian students have had physical contact or intimate relationship with the opposite sex, but our results show that Bosnian students have more free and expressive attitudes towards romantic love. Still, in dept investigation would be worthwhile and would give us more conclusive data.

Kin Ng and Cheng (2010), also found some cultural impact on love, operationalized with Triangular Scale of Love. They found that in western cultures, satisfaction with

Epiphany: Journal of Transdisciplinary Studies, Vol. 7. No. 2, (2014) (C Faculty of Arts and Social Sciences 
romantic relationship was mediated with intimacy and passion, while in research made on Chinese people, satisfaction with relationship was mediated with intimacy and commitment.

Another goal of this research was to investigate eventual gender differences in Triangular Scale of love results. According to the table 4 there are no statistically significant differences between male and female on any of the three components of Triangular scale. It would be logical to assume that there would be some differences, since male and female have different needs and attitudes when it comes about a lot of things, especially about love. It would be logical to suppose that male will evaluate higher passion, while female will strive for commitment and intimacy. Also, there results were checked by one - way ANOVA, ant results show that there are no gender differences.

Sternberg (1997) found in his research that woman had higher intimacy ratings, while on other components there were no statistically significant difference. It might be that male and female really do not have different needs and perception of love, but it is just a prejudice that male are more addicted to physical component which is related to passion, while female look for more intimacy in term of psychological support. It would be worth to check it with some similar research, are male really more directed to fulfilling physical needs in romantic relationship.

2. Correlation between the length of relationship and three aspects of Triangular Scale of Love and Close Relationship Emotion Questionnaire.

The length of relationship was measured in months and it is correlated with three dependent variables: Intimacy, Passion and Commitment.

Table 5. Correlations between length of relationship and three components of TLS

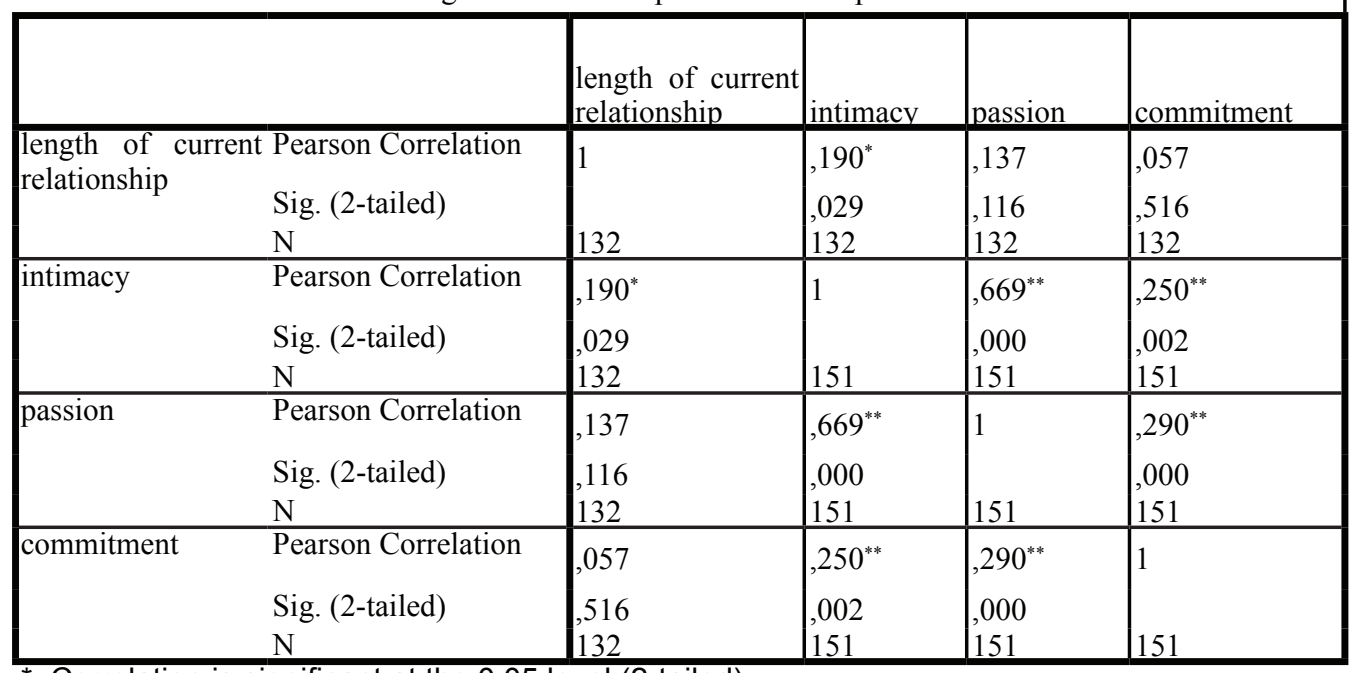

*. Correlation is significant at the 0.05 level (2-tailed).

${ }^{* *}$. Correlation is significant at the 0.01 level (2-tailed). 
From the table 5 , it can be seen that high and statistically significant correlations are found only between three components of Triangular Scale of Love: intimacy, passion and commitment. These results completely support findings from Sternberg (1997), where he found that three components covariate, instead of being independent. Results of this study also point to significant and positive correlations between intimacy and passion $\left(, 669^{* *}\right)$, and also intimacy and commitment $\left(, 250^{* *}\right)$, and commitment and passion $\left(, 290^{* *}\right)$. First correlation is significantly high which means that if the couple is more intimate, if it shares more psychological support, that passion will also be higher, and vice and versa. Two other correlations have the same direction.

Length of the current relationship is correlated with intimacy, but quite correlation, which is positive $\left(\mathbf{1 9 0}^{*}\right)$. This means that the longer the relationship is, it is related to more intimate relationship and vice and versa. Sternberg (1986.) claims that these components may be used independently to examine their association to individual (e.g., psychological well-being) and relationship (e.g., satisfaction and quality) outcomes. For example, Overbeek, Ha, Scholte, de Kemp, and Engels (2007) found that each TLS construct was positively associated with the satisfaction and longevity of heterosexual adolescents' romantic relationships. And the area of the love triangle, representing the intensity of intimacy, passion, and commitment experienced by a person, is positively related to his or her perceived relationship quality.

It has also been documented that the triangular love components are associated with other measures of relationship quality. Whitley's (1993) study with a sample of female college students revealed that the levels of the love components were related to actual stability and expected stability. The studies of Hendrick and Hendrick (1988) found moderate correlations between the love components and the relationship quality factors such as viability, caring, global satisfaction, and conflict.

This research though found that length of relationship is correlated with intimacy, as the only dimension of Triangular Scale of Love, while other correlations were not found. Therefore, it would be worthy of further investigation and exploring other, related aspects, including adults who are in relationship for longer period of time besides students.

\section{Conclusions}

This study shows that there are statistically significant differences between Turkish and Bosnian students in Intimacy and Passion subscales on Triangular Scale of Love, with Bosnian students having higher results in subscales of Intimacy and Passion. At the same time, results point to no statistically significant difference in subscale of Commitment. This might be due to the cultural differences between Bosnian and Turkish students. Our results show that while there are no significant differences on Commitment on triangular love scale, the two groups have significantly different results in subscales of Intimacy and Passion. This might be explained by likely influence of cultural background, Western in terms of Bosnian or Eastern in terms of Turkish students, which might have an impact on students' perception of love, especially perception of Intimacy and Passion. The so called free love practiced with precautionary measures, type of behavior disapproved by

Epiphany: Journal of Transdisciplinary Studies, Vol. 7. No. 2, (2014) (C Faculty of Arts and Social Sciences 
parents and teachers and subjected to parental discipline in Turkish (Eastern) culture, seems more acceptable in Bosnian (European) culture. It seems that Bosnian students, although by religious orientation closer to Eastern culture, being a part of Europe and European culture, adjusted their perception of what their religion states, to the main stream (Western) attitudes towards intimate relationships. Practicing Muslims (strictly adhering to religious rules) are minority in Bosnia thus adolescents find it difficult to adhere and observe all religious practices especially in intimate relationships.

Also, despite the overall gender differences in terms of emotions, we found no significant differences between males and females on any of the three components of Triangular love Scale. This means that males and females do not differ in terms of perceiving Love, Intimacy, Passion and Commitment. Adolescence is turbulent time, time for testing and experiencing many things, time for looking for approval and giving in to peer pressure, what makes it equally challenging for girls and for boys.

Finally, as stated in the third goal of this research, we explored correlation between the length of relationship and results on subscales of TLS. Results show that the length of the current relationship is correlated with Intimacy, but correlation which is positive is low. Therefore, we can conclude that longer relationship is related to more intimate relationship, and vice and versa.

\section{References}

Badhwar, N., K., (2003). "Love”, in H. La Follette (ed.), Practical Ethics, Oxford: Oxford University Press, $42-69$.

Borland, Dolores M., (1975). „An Alternative Model of the Wheel Theory.“ The Family Coordinator 24(3): 289-292.

Brown, R., (1987). Analyzing Love, Cambridge: Cambridge University Press.

Corsini R. J. and Auerbach A. J. (1998). Concise Encyclopedia of Psychology, John Wiley and Sons, INC, USA.

Feldman, Robert S., (2006). Human Development across the Lifespan (4th ed). New Jersey: Pearson Education.

Hatfield, E., \& Rapson, R. L., (1993). Love, sex, and intimacy: Their psychology, biology, and history. New York: Harper and Collins.

Hatfield, E., \& Rapson, R. L. (1994). Love and intimacy. Encyclopedia of Mental Health. 2. New York: Academic Press.

Hendrick, S. S., Hendrick, C., \& Adler, N. L. (1988). "Romantic relationships: Love, satisfaction, and staying together." Journal of Personality and Social Psychology, 54(6), 980-988.

Kin Ng T. \& Cheng K.,H.K., (2010). "The Effects of Intimacy, Passion, and Commitment on Satisfaction in Romantic Relationships among Hong Kong Chinese People." Journal of Psychology in Chinese Societies Vol. 11, No. 2, 123-146.

Lee, J. A., (1973). The colors of love: An exploration of the ways of loving. Toronto: New Press.

Niedenthal, Paula M., Silvia Krauth-Gruber, Francois R., (2006). Psychology of Emotion Interpersonal, Experimental, and Cognitive Approaches. New York, NY: Psychology Press.

Overbeek, G., Ha, T., Scholte, R., de Kemp, R., \& Engels, R., (2007). Brief report: Intimacy, passion, and commitment in romantic relationships-Validation of a 'triangular love scale' for adolescents. Journal of Adolescence, 30, 523-528.

Plotnik R. \& Kouyoumdjian H., (2011). Introduction to Psychology. Wadsworth Cengage Learning, USA. Rathus, S. A., (2000). Temelji psihologije. Naklada Slap, Jastrebarsko.

Reiss, Ira L., (1960). Premarital Sexual Standards in America: a sociological investigation of the relative

Epiphany: Journal of Transdisciplinary Studies, Vol. 7. No. 2, (2014) (C) Faculty of Arts and Social Sciences 
social and cultural integration of American sexual standards. The Free Press.

Rot, N., (2004). Opšta psihologija, Zavod za udžbenike i nastavna sredstva, Beograd.

Rubin, Z., (1973). Liking and loving: An invitation to social psychology. New York, Holt, Rinehart and Winston.

Rubin, Z. (1970) Measurement of romantic love. Journal of Personality and Social Psychology, 16, 265273.

Sternberg, R. J., (1997). Construct Validation of a triangular love scale, European Journal of Social Psychology, Vol. 27, 313-335

Sternberg, R. J., (1986). A triangular theory of love, Psychological Review, 93, 119-135.

Sternberg, R. J., \& Barnes, M. L., (Eds.). (1988). The psychology of love. New Haven, Yale University Press.

Whitley, B. E., (1993). Reliability and aspects of the construct validity of Sternberg's triangular love scale. Journal of Social \& Personal Relationships, 10(3), 475-480.

Wittig A. F., (2001). Introduction to Psychology. New York, McGraw-Hill. 